\title{
The future of resilient supply chains
}

\author{
Mattia Donadoni (mattia.donadoni@polimi.it), \\ Politecnico di Milano, Milan, Italy \\ Sinéad Roden \\ Trinity Business School, Trinity College Dublin, Dublin, Ireland \\ Kirstin Scholten \\ University of Groningen, Groningen, The Netherlands \\ Mark Stevenson \\ Lancaster University, Lancaster, United Kingdom \\ Federico Caniato \\ Politecnico di Milano, Milan, Italy \\ Dirk Pieter van Donk \\ University of Groningen, Groningen, The Netherlands \\ Andreas Wieland \\ Copenhagen Business School, Frederiksberg, Denmark
}

\begin{abstract}
While supply chain resilience has been touched upon frequently, research remains (with the exception of often repeated anecdotal examples) relatively disparate on what disruptions actually are. This research aims to advance theoretical and managerial understandings around the management of supply chain disruptions. A two-stage research process is used which focuses first on polling academic experts. This stage is followed by the extraction of insights from practitioners in the automotive, electronics and food industries. Our findings coalesce around: (1) the types of disruptions that respondents are most concerned about; (2) the associated strategies suggested to cope with disruptions; and, (3) how resilience can be measured. It is apparent that there are some areas where academics and practitioners agree and others where they agree to a lesser extent. Both sets of actors tend to agree on how resilience can be quantified, with recovery time the preferred indicator. However, there is a discrepancy around how resilience is achieved within the supply chain. Academics emphasise the importance of redundancy while practitioners refer more to flexibility. Also, they disagree around what constitutes 'key
\end{abstract}


disruptions': academics suggested high-profile events while practitioners are more concerned with day-to-day problems.

Keywords: Supply chain resilience; Expert interviews; Disruption

\section{Introduction}

Dynamism coupled with market instability continues to expose supply chains to disruptive events. The occurrence of disruptions cannot only be traced back to the multitiered and global nature of many supply chain configurations (Christopher and Peck 2004a; Jüttner and Maklan 2011; Sheffi and Rice 2005), but also to their interconnectivity (Knemeyer et al., 2009; Bakshi and Kleindorfer, 2009). As a result, supply chain disruptions are inevitable events and a key contemporary challenge concerns how organisations and supply chains can bounce back while ensuring sustained performance outcomes (Ponomarov and Holcomb 2009). In other words, how they can improve their ability to handle disruption, thereby creating and developing a resilient supply chain.

The resilience of organisations and their supply chains has become a focal point of interest for practitioners and academics alike over the past ten years (for a review, see Tukamuhabwa et al., 2015). This interest has been sparked by the severe impact that disruptions can have at the firm level and beyond, in terms of both short and longer term operational and financial performance (Hendricks and Singhal 2005). Considerable attention in the literature has been given to a number of devastating examples in the last decade (e.g. the financial crises (Jüttner and Maklan 2011); the Tōhoku earthquake and tsunami and Hurricane Sandy) which highlight how disruptions that occur at one node, cascade through the network. As such, the evolving empirical literature has made steady progress in measuring "disruptive events" and operationalizing resilience. At the same time, less attention has been given to what "keeps managers awake at night" - what the things are that they are most concerned about. In particular, there is little knowledge about what they consider as a disruption in day-to-day management of their supply chain, what they perceive as resilience and how to measure it. We are also not clear on whether the definitions and measurement of resilience depend on industry context, specific organisational capabilities or supply chain strategies they employ. Against this backdrop, we aim to disentangle the concept of supply chain resilience (SCRES) and understand how it is interpreted in practice. 
A two-stage empirical study has been conducted. The first stage was performed with academic experts in the field of SCRES to identify key disruptions, strategies, resilience metrics, and industries where resilience is expected to be a key concern. This stage helped to set the scope of the research and identify target respondents for the following stage. Hence, based on the responses of the first stage, we involved practitioners from three industries: automotive, electronics and food, to capture what it means to be resilient in a practical context in the second stage. Their insights allow us to theorise about three aspects related to disruptions in and resilience of global supply chains:

- the nature and characteristics of key disruptions

- the features that make an industry or supply chain vulnerable or prone to disruption

- the features of the primary strategies employed to avoid or minimise the effects of a disruption and 'bounce back'

The remainder of this chapter is organised as follows. In Section 2, we develop our lines of enquiry using SCRES literature. Section 3 describes the methodology adopted, with the results from stages 1 (academic experts) and 2 (practitioner experts) presented in Section 4, followed by a discussion in Section 5. The chapter concludes in Section 6, which includes avenues for future research on SCRES.

\section{Theoretical Background}

Disruptions are defined as "unplanned and unexpected events that interrupt the flow of materials and products within a supply chain" (Hendricks and Singhal 2005). A wide variety of events can potentially cause a disruption including unavailable raw materials, late deliveries, natural disasters, tainted ingredients, government regulations, machine breakdowns, and cyber threats (Business Continuity Institute 2016). Clearly, this set of disruptions is hierarchical and inter-related; for example, a natural disaster could affect the availability of raw materials and the on-time performance of deliveries. As such, disruptions can have different degrees of severity (Craighead et al. 2007) and consequences (e.g. operational and financial), both within and across organisations (Bode et al. 2011; Craighead et al. 2007) that can compromise not only the ability to manufacture products but also to fulfil market requirements. While research has classified disruptions according to their impact (high, medium or low impact, e.g. Norrman and Jansson (2004) and Tang, (2006)) to derive appropriate risk management strategies, others have approached the evaluation of disruptions according to the probability of occurrence and the relative magnitude (Ellis et al. 2010). Other classifications may however be 
appropriate; for example, it may be important to treat disruptions according to their origin or duration. Therefore, our first research question aims to understand the characteristics of disruptions as a starting point for determining how to treat them in the future:

\section{RQ1: What are the characteristics of supply chain disruptions that decision makers work to actively avoid?}

The severity of the disruption is affected by the portfolio of resources that companies possess. Indeed, the mitigation capacity of companies is strictly related to resources that can be deployed to reduce the initial impact and overcome the supply chain disruption. According to Sheffi and Rice (2005), companies that can shape their resources towards the development of an effective strategy for dealing with disruptions can improve their resilience. With this in mind, the SCRES literature has highlighted various strategies for dealing with disruptions in supply chains and enhancing resilience (Pettit et al., 2010; Tukamuhabwa et al., 2015). Given this, the majority of the works remain mostly conceptual, leaving a sense of ambiguity on how resilience can be fostered within organisations and in their relative supply chains, as described below.

One of the first studies on resilience in supply chains was conducted by Rice and Caniato (2003) who described two main strategies for achieving resilience - having redundancy to quickly deploy extra resources in case of emergency and being flexible to adapt to fluctuations in the business environment. Similarly, Wieland and Wallenburg (2013) argue that the resilience of a supply chain relates to a proactive ("robustness") and a reactive strategy ("agility"), the former often being built on redundancy, the latter on flexible adaptation. Christopher and Peck (2004) proposed four system level strategies: re-engineer the supply chain; collaborate with other entities; improve agility; and, create a supply chain risk management culture. Other studies have elaborated on formative elements such as flexibility, velocity, visibility, and collaboration (Jüttner and Maklan, 2011), or the human resources (e.g. training or education) as main facilitators of resilience (Blackhurst et al. 2011). Furthermore, some authors distinguish between intra- and interorganizational antecedents of resilience (Durach et al. 2015).

Although these earlier academic studies have made progress in disentangling the concept of SCRES and identifying how resilience can be fostered, empirical understanding and support of which activities, routines, and strategies are actually adopted by managers remains underdeveloped. It is also uncertain how the strategies employed in practice compare, e.g. whether they have similar features or characteristics, 
which could allow for a more general contribution to understanding how resilience can be developed. Therefore, our second research question asks:

RQ2: What are the activities and strategies that organisations use to mitigate disruptions and bounce back?

So far, the SCRES literature has focused on identifying the strategies that companies can apply to make the whole supply chain resilient, but there is a lack of understanding whether the business environment in which companies operate influences the portfolio of strategies embraced by firms. To this regard, it has been suggested that determining appropriate practices for dealing with disruptions can be context-specific (Christopher and Peck 2004b). Contextual problems that plague one industry can drive the approaches adopted to build resilience by companies towards a specific set of strategies; and the context could also influence the behaviour of managers when they are faced with a disruption. So far it is unclear if, and if so, how, the characteristics of an industry relate to resilience and disruption. Taking industry features (e.g. product life cycles, supply chain characteristics, technology ratios, power structure) into consideration may help to shed light on how they shape the boundaries and capabilities through which companies build resilience. Indeed, industry characteristics might impact the frequency, magnitude, and duration of disruptive effects. Hence, some industry types may be perceived to be more prone to disruption than others. Therefore, the third research question is:

\section{RQ3: What are the characteristics of industries that make them more or less prone to a} disruption?

Even within an industry sector, there are differences between organisations regarding how they manage disruptions and develop their 'resilience'. The well-known case of Nokia vs. Ericsson, for example, demonstrates that some organisations are more resilient than others (Norrman and Jansson 2004). So far, however, we only know how resilient a supply chain is when it is too late, i.e. after it has faced a disruption when we can reflect on the impact of the event; and the academic literature offers only limited insight into this issue. There is a lack of understanding of how resilience is currently measured or assessed by organisations across sectors. According to Barroso et al., (2015) the question of "how to assess the supply chain resilience" remains unanswered.

To date, the closest metric for evaluating resilience relies on the concept of the "resilience triangle", which captures the loss in performance after a disruption has 
occurred (Tierney and Bruneau 2007). The magnitude of a disruption influences the depth of the triangle while the recovery time affects the length of the triangle. The approach allows for understanding the resilience level of companies after a disruptive event has occurred - evaluating the size of the disruption and the recovery - but it is not able to evaluate (potential) resilience proactively. Moreover, it is not clear how to evaluate the impact of the various strategies that companies implement to enhance resilience. Being able to estimate the current resilience value of each entity within a supply chain in advance of a disruption would help managers to justify investments in areas that attenuate the negative and unpredictable effects of disruptions. Further, being able to quantify the level of resilience would allow stakeholders to identify the weakest node in the supply chain, invest resources and deploy strategies in an efficient way to improve the overall level of resilience. Therefore, the final research question is:

RQ4: How can supply chain resilience be measured by organisations?

\section{Research Methodology}

This work follows a qualitative approach in our data gathering, relying on statements and answers of two panels of experts in the field of SCRES: academics and managers. In line with the aim of this research, engaging experts on resilience helps in exploring different points of view on a phenomenon as complex as resilience. Our study comprises the following two stages in order to both capture some of the existing knowledge among academics as well as get a more detailed and nuanced view on managers' insights:

- Stage 1: Data is used from a panel of academic experts who are active in the field of SCRES.

- Stage 2: Data is used from a panel of practitioner experts from industries identified as being particularly prone to disruption by the academic experts (automotive, electronics, and food).

\subsection{Data Collection and Analysis}

\section{Stage 1: Involving Academic Experts}

We targeted academic experts who have contributed to the supply chain resilience literature in the past ten years. A total of 36 academic experts were sent an invitation letter outlining the conceptual background and purpose of the study. Given the exploratory nature of this stage, the questionnaire was based on open-ended questions regarding: (1) 
key disruptions; (2) resilience strategies; (3) industry risk levels; and, (4) metrics for measuring resilience in line with the four research questions of this study. Responses were received from 23 of the academic experts contacted, i.e. a response rate of 64\% (Table 1). From the original list of responses, we eliminated those that did not provide any valuable insights (e.g. respondents who were not able to provide any metrics to calculate resilience) or we merged similar answers for having distinguished and concise options (e.g. respondents who stated "quality related problems" with others like "parts quality" by creating one single label like "quality incident"). The main goal at this stage was to obtain a list of potential responses to be used for structuring the questionnaire for the second stage of the study and for selecting the right target practitioners.

Table 1 - Descriptive information about respondents in the study (Stage 1)

\begin{tabular}{lcc}
\hline \multicolumn{1}{c}{ Country } & N & \% \\
\hline UK & 8 & $35 \%$ \\
United States & 5 & $22 \%$ \\
Italy & 2 & $9 \%$ \\
Germany & 2 & $9 \%$ \\
Switzerland & 1 & $4 \%$ \\
Japan & 1 & $4 \%$ \\
Denmark & 1 & $4 \%$ \\
Portugal & 1 & $4 \%$ \\
Netherlands & 2 & $9 \%$ \\
Total & $\mathbf{2 3}$ & $\mathbf{1 0 0 \%}$ \\
\hline
\end{tabular}

\section{Stage 2: Involving Practitioner Experts}

The objective of this second round was to obtain a ranking classification around the most feared disruptions, deployed strategies for handling disruptions, and how resilience is actually measured by organisations. In this regard, the results from Stage 1 enabled a more structured questionnaire design for Stage 2: from the original list of disruptions (question 1) and resilience strategies (question 2) generated, the seven highest-ranking options and for the measurement of resilience (question 4) the four highest ranking options were identified. We developed a 7-point scale for practitioners to evaluate the importance of each item (e.g. with (1) "most important threat" to (7) "least important threat"). Furthermore, we selected the three highest scoring industries in terms of risk (question 3) for practitioner respondent selection i.e. automotive, electronics and food.

90 practitioners across Europe that were considered to be specialists in the area of SCRES, or knowledgeable of their organisation's supply chain risk management strategy, 
were contacted. Responses from 43 practitioners (response rate of 48\%) were received. Additionally, respondents were also asked to comment upon their choice of answers so as to provide further context and background. Table 2 provides descriptive statistics on the respondents. The majority of companies involved in this stage are food companies (63\%), followed by electronics companies (21\%) and automotive companies (16\%).

\section{Results \& Discussion}

\subsection{Insights from the Academic Panel}

\subsubsection{Key Disruptions that Decision Makers Actively Work to Avoid or Eliminate}

The data from the academics on key disruptions were classified to obtain a clearer picture of the items listed. The original list of disruptions was quite heterogeneous regarding the nature of the problems and contained different answers. Indeed, we obtained rich information regarding key disruptions, but in turn, some answers were at a different level of categorisation. For instance, some respondents provided precise disruptions (e.g. earthquakes, flood, quality related problems or counterfeiting) while others just listed some classification like "operational disruptions" or "everyday disruptions". So, initially, we grouped those options by classifying them according to the Tang (2006) framework for distinguishing them between operational (small to medium impact) and disruption risks (high-impact). Then, we enlarged the nomenclature by looking for well-known risks (e.g. unplanned IT or telecom outages, adverse weather, strikes and currency exchange rate volatility) (Business Continuity Institute 2016). Such procedures helped in having a list of unique elements both "operational" and "high profile" events. The results are shown in Table 3 listed according to the percentage of respondents referring to a particular type of disruption.

Concerning the first research question (RQ 1), when we consider Table 3, we can see that academics are more concerned with large-scale, high-profile disruptions related to network disasters, insolvency in the supply chain and demand-side issues (such as demand forecasting, loss of customers or problems in complying with customer's requirements). These types of disruptions align with recent conceptualizations of supply chains as networks and embraces both physical and support supply chains (Carter et al. 2015). The SCRES literature is grounded in the notion that resilience should be designed into supply chains as a primary feature for responding to unforeseeable and extreme events. 
Table 2 - Descriptive information about respondents in the study (Stage 2)

\begin{tabular}{lcc}
\hline Company Employees & $\mathbf{N}$ & $\mathbf{\%}$ \\
\hline $1-200$ & 7 & $16 \%$ \\
$201-500$ & 2 & $5 \%$ \\
$501-1000$ & 1 & $2 \%$ \\
$1001-5000$ & 3 & $7 \%$ \\
$5001-10000$ & 3 & $7 \%$ \\
$10001-25000$ & 6 & $14 \%$ \\
$25000+$ & 21 & $49 \%$ \\
Total & $\mathbf{4 3}$ & $\mathbf{1 0 0 \%}$ \\
& & \\
\hline Industry & $\mathbf{N}$ & $\mathbf{\%}$ \\
\hline Food & 27 & $63 \%$ \\
Electronics & 9 & $21 \%$ \\
Automotive & 7 & $16 \%$ \\
Total & $\mathbf{4 3}$ & $\mathbf{1 0 0 \%}$ \\
& & \\
\hline Country & $\mathbf{N}$ & $\mathbf{\%}$ \\
\hline Germany & 4 & $9 \%$ \\
Netherlands & 19 & $44 \%$ \\
Spain & 1 & $2 \%$ \\
Sweden & 1 & $2 \%$ \\
Turkey & 1 & $2 \%$ \\
UK & 5 & $12 \%$ \\
United States & 1 & $2 \%$ \\
Italy & 10 & $23 \%$ \\
Switzerland & 1 & $2 \%$ \\
Total & $\mathbf{4 3}$ & $\mathbf{1 0 0 \%}$ \\
& & \\
\hline
\end{tabular}

\subsubsection{Strategies Employed to Enable Organisations to Cope with Disruptions}

Academic respondents were also asked to identify strategies that may be employed to mitigate the harmful effects of disruptions. Indeed, to address the second research question (RQ 2), an overview of strategies for fostering resilience was sought. The data on key resilient strategies were classified based on previous categorizations (Pettit et al. 2010; Tukamuhabwa et al. 2015) to obtain a clearer picture of the items listed. Accordingly, we grouped similar responses under the same strategy to make them comparable. For example, in line with SCRES literature (Tukamuhabwa et al., 2015; Hohenstein et al., 2015) we grouped answers such as postponement or modular product designs under the heading of flexibility. These strategies are shown in Table 4.

Eighteen heterogeneous strategies were highlighted by the respondents, with redundancy (e.g. having additional inventory, capacity or suppliers to allow a company to promptly 
cope with and overcome a disruptive event), overwhelmingly selected as the key strategy for enhancing resilience.

Table 3 -Relevance of supply chain disruptions according to the academic experts

\begin{tabular}{lc}
\hline Supply Chain Disruptions & Respondents (\%) \\
\hline Network issue & $73 \%$ \\
Insolvency in the supply chain & $40 \%$ \\
Demand-side issue & $33 \%$ \\
Quality incident & $27 \%$ \\
Natural disaster & $27 \%$ \\
Unplanned IT or telecom outages & $20 \%$ \\
Machine breakdown & $20 \%$ \\
Counterfeiting & $13 \%$ \\
Strike & $13 \%$ \\
Act of terrorism & $13 \%$ \\
Fire & $13 \%$ \\
Business ethics incident & $13 \%$ \\
New laws, regulations & $13 \%$ \\
Currency exchange & $13 \%$ \\
Cyber attack & $7 \%$ \\
Civil conflict, political uncertainty & $7 \%$ \\
Intellectual property violation & $7 \%$ \\
Health and Safety incidents & $7 \%$ \\
\hline
\end{tabular}

Additional capacity, stock or suppliers are resources that can be immediately used during a disruption. Business continuity plans are cited also as an important resilience mechanism. Perhaps unsurprisingly, managers tend to rely mainly on flexibility coupled with a set of other strategies. Flexibility is defined as "the ability to react or transform with minimum penalties in time, cost, and performance" (Upton 1997). Building on this, practitioners deploy strategies that help them to quickly reconfigure activities for matching changes in their business environment. Strategies which are not strictly designed for creating resilience (e.g. collaboration, supply chain design) are deployed on a daily basis mainly for cost efficiency goals, but in turn, help companies in dealing with a different spectrum of risks. Practices such as information sharing with customers and suppliers, long-term agreements, and customers and suppliers' co-development are all practices that can enhance a collaborative approach within supply chains (Handfield and Bechtel 2002; Spekman 1988). Looking at such strategies, it is worthwhile emphasising their variety: ranging from close relationships with upstream/downstream partners (e.g. 
creating a collaborative approach to share information) to internally focused organisational effort (e.g. building safety stock).

Table 4 - Resilience strategies identified by the academic experts

\begin{tabular}{lc}
\hline Resilience Strategies & Respondents (\%) \\
\hline Redundancy & $83 \%$ \\
Business continuity planning & $43 \%$ \\
Flexibility & $39 \%$ \\
Collaboration & $39 \%$ \\
Supply chain design & $30 \%$ \\
Visibility & $13 \%$ \\
Insurance & $13 \%$ \\
Building Security & $9 \%$ \\
Contracts & $4 \%$ \\
Safety rules & $4 \%$ \\
Training competitors & $4 \%$ \\
Emergency centre & $4 \%$ \\
Hedging for commodity price risk & $4 \%$ \\
Resilience software & $4 \%$ \\
Quality practices & $4 \%$ \\
Financial solutions & $4 \%$ \\
Risk management practices & $4 \%$ \\
Supplier evaluation & $4 \%$ \\
\hline
\end{tabular}

\subsubsection{Industries Perceived to be the Most Prone to Disruption}

The third research question (RQ 3) examines the impact of industry on resilience. Specifically, respondents were asked to list the industries they anticipated as being particularly prone to disruption. The results are presented in Table 5 where the top three industries are automotive, electronics and food. While it has been acknowledged that organisational resilience strategies can be influenced by the nature of business and industry in which the business resides (Christopher and Peck 2004a), the SCRES literature provides few insights on this. Our study helps to better understand this claim. Specifically, automotive and electronics industries are complex and global, in which numerous entities are involved (e.g. a multitude of tiers) as the products are built using a large number of heterogeneous parts. Such inherent factors contribute to exposing automotive and electronics companies to a higher level of complexity and ultimately, vulnerability. Moreover, given the complexity of these supply chains, it is difficult to closely monitor these chains for potential disruptions since companies lack visibility of 
their supply chains. Results also suggested that the food industry is vulnerable to disruption. In particular, academics referred to the effects of specific risks that are part of the context that can increase the level of vulnerability. One academic stated: "the process industry and particularly the food industry is prone to disruptions as operations take place 24/7 and perishability adds another dimension to managing disruptions." Given that food products may have perishability constraints, may be based on raw materials with volatile demand and supply markets and/or prone to contamination (2013 EU horse-meat scandal) and food safety concerns, this result is perhaps not a surprise.

\subsubsection{Metrics for Assessing Supply Chain Resilience}

Finally, the last research question (RQ 4) aimed to identify common approaches to the measurement of resilience. Thus, academic experts were asked to list the key metrics for evaluating resilience. This remains an unresolved issue in the literature, reflected in the diversity of answers that range from metrics such as the recovery time to general performance frameworks such as SCOR. Hence, while our results in Table 6 include some clear metrics that can be used to measure resilience, other responses cannot be directly used to measure the level of resilience. We therefore assume that this question was rather difficult to answer for the academic experts.

Table 5 -Industries perceived to be the most prone to disruption by the academic experts

\begin{tabular}{lc}
\hline Industries & Respondents (\%) \\
\hline Automotive & $60 \%$ \\
Electronics & $33 \%$ \\
Food & $33 \%$ \\
High-tech & $20 \%$ \\
Fashion & $20 \%$ \\
Aerospace & $20 \%$ \\
IT & $13 \%$ \\
Pharmaceutical & $13 \%$ \\
Chemical & $7 \%$ \\
Banking & $7 \%$ \\
Retailing & $7 \%$ \\
Logistics & $7 \%$ \\
\hline
\end{tabular}

The most commonly cited metric is recovery time. Almost all respondents agreed with the idea of calculating the interval in time between the occurrence of a disruption and full 
recovery. Although the recovery time is commonly used in the literature as a proxy for estimating resilience, it can typically only be evaluated after a disruption has occurred and hence does not help in measuring the level of resilience of a supply chain or organization in advance.

Table 6-List of resilience metrics

\begin{tabular}{lc}
\hline Metrics & Respondent (\%) \\
\hline Recovery time & $73 \%$ \\
Recovery cost & $20 \%$ \\
Market share (before and after disruption) & $20 \%$ \\
Contingency strategies cost & $13 \%$ \\
Supply Chain Resilience Assessment and Management (SCRAM) & $13 \%$ \\
Customer service & $7 \%$ \\
Suppliers' dependency (first tier, second tier) & $7 \%$ \\
Time to survive & $7 \%$ \\
Supply Chain Risk Management Maturity Model & $7 \%$ \\
Value at Risk & $7 \%$ \\
Supply Chain Operations Reference model (SCOR) & $7 \%$ \\
\hline
\end{tabular}

This also applies to the second most referred to metric i.e. recovery cost, which entails the total cost incurred by the company to recover from disruptions. Similarly, the contingency strategy cost which expresses the total cost needed for implementing such strategies required for counteracting the detrimental effects of disruptive events. More generally, the measures can be grouped into cost related factors and time related ones, while another distinction is between - uninterrupted - performance measures and preventative ones.

\subsection{Insights from the Practitioner Panel}

\subsubsection{Key Disruptions that Decision Makers Actively Work to Avoid or Eliminate}

In answering the first research question, practitioners were asked to score the seven most frequently referred to disruptions from Stage 1, in terms of relevance to their organisation (on a seven-point scale with 1 being the most important threat and 7 the least important threat). Results are presented in Figure 1. The most feared disruption according to the practitioners is a quality incident arising from product and/or service issues. Indeed, quality problems can compromise the ability to fulfil market requirements and guarantee the sustainability of the business. For instance, one of the participants stated that "focus 
on quality is key for long-term performance". Besides, quality issues can also potentially impact how consumers perceive the image as "managing quality problems helps them avoid reputational damage".

The second most feared disruption is caused by demand risk, followed by network risk. The former entails demand fluctuations, the entry of new competitors, and changes in customer requirements; and the latter is related to upstream and downstream flows. Network risk includes all problems arising from a network perspective, which includes the physical and support supply chains (Carter et al., 2015). The global nature of today's supply chains can be a key issue for managing business efficiently as for example when companies "import products from different countries into Europe, we have to work with transport delays which lead to production delays". In the middle of the ranking, practitioners positioned disruptions like supplier insolvency and machine breakdowns. The least relevant disruption is a natural disaster. This is an interesting result considering that the origins of supply chain resilience literature lie in the analysis of low probability and high impact events but, according to our findings, practitioners seem to pay little attention to natural disasters. In this regard, the supply chain disruption characteristics which drive the decision-makers are the tangibility of such problems which shape their behaviour and helps them in perceiving the potential detrimental effects immediately (e.g. quality problems). Besides, even though high-impact events attract the attention of scholars and affect companies severely, practitioners still tend to ignore them.

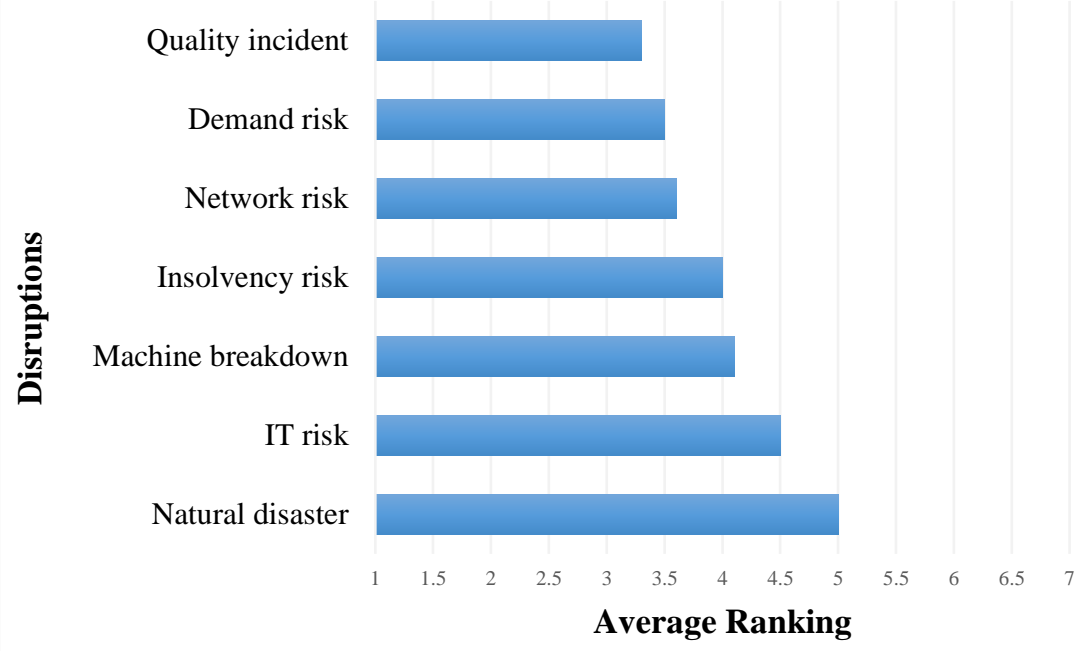

Figure 1 - Disruptions feared by the respondents (from "1" most to "7" least feared) 


\subsubsection{Strategies Employed to Enable Organisations to Cope with Disruptions}

Practitioners were asked to rate the seven most frequently referred to supply chain strategies from stage 1 for coping with disruptions (on a seven-point scale with 1 the most commonly employed strategy and 7 the least commonly strategy employed). Such list derived from stage 1 helped in linking findings to the second research question. Figure 2 depicts that flexibility is the leading strategy applied by managers for overcoming the detrimental effects of a disruption. Flexibility can improve the ability to adapt operations to face up to a misalignment in the environment quickly. For instance, one of the practitioners explained: "when we face disruptions, our type of approach is production anticipation or postponement to fulfil our customers' orders."

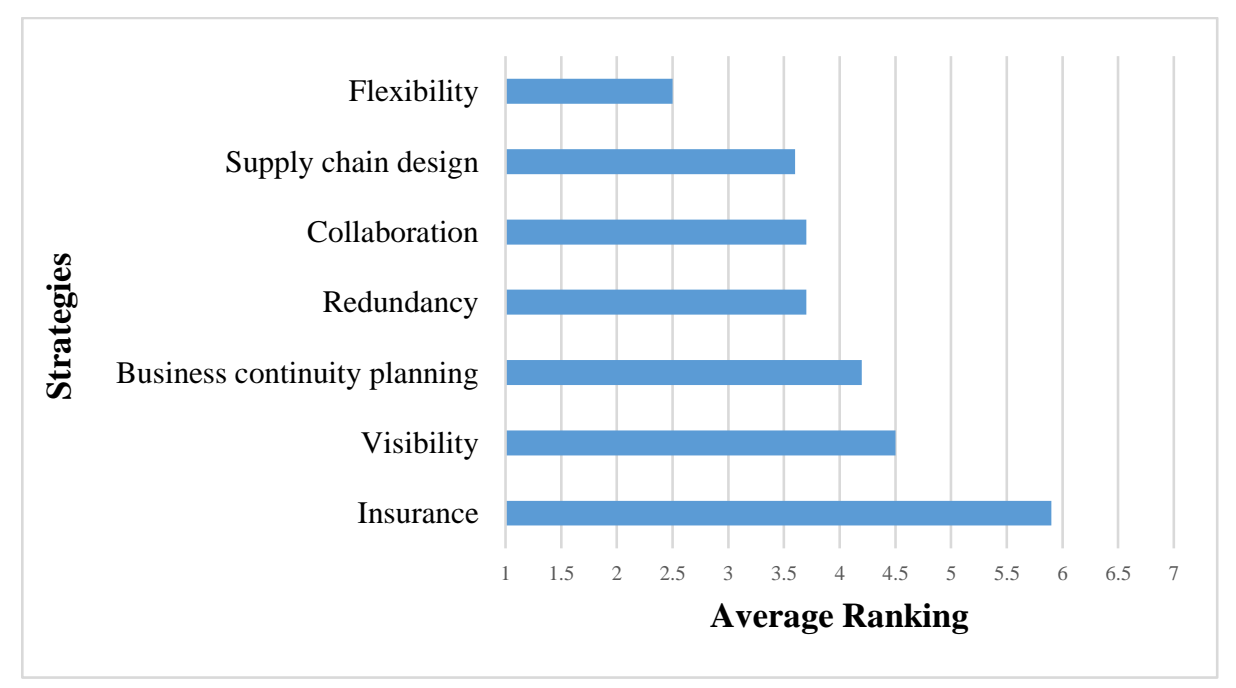

Figure 2 - Strategies employed to cope with disruptions (from "1" most to "7" least commonly employed)

According to the results, practitioners tend to rely on supply chain design, embedding redundancy (e.g. additional capacity, extra stock), and collaborating upstream and downstream in the chain with almost the same level of importance. The importance attached to these strategies aligns with the SCRES literature. Supply chain design is a proactive strategy that allows a manager to switch from one option (e.g. a supplier) to another if needed. Redundancy is typically associated with resilience because it is a straightforward but at the same time very expensive strategy (Tukamuhabwa et al. 2015) that a company can chose to apply as a first response to disruptions. Collaboration upstream and downstream embraces the ability to work jointly towards a common goal where, in the case of a disruption, there is a reduction of resources and efforts are required to monitor the disruption and put in place a mitigation and recovery strategy. Practitioners 
then referred to business continuity planning and visibility. To a certain degree, this is a surprising result since visibility is one of the most quoted strategies in the SCRES literature. The least deployed strategy is insurance, which is associated with the ability to cover financial losses; but it is not able to guarantee continuity in case of operations problems and can only partially cover the detrimental consequences of disruptions. It suggests that our respondents tend to think more in terms of customers' satisfaction than in terms of money lost.

\subsubsection{Metrics for Assessing Supply Chain Resilience}

Practitioners were asked to rate four metrics from Stage 1 for evaluating the level of resilience (on a four-point scale with 1 being the most important measurement and 4 the least important measurement). Due to the diversity of answers, we opted for a four-point scale, as we used the clear metrics proposed that can be used to measure resilience. Thus, we dropped those answers that cannot be directly used to measure the level of resilience (e.g. SCOR). Figure 3 shows the results, which helped us to cover the last research question (RQ 4).

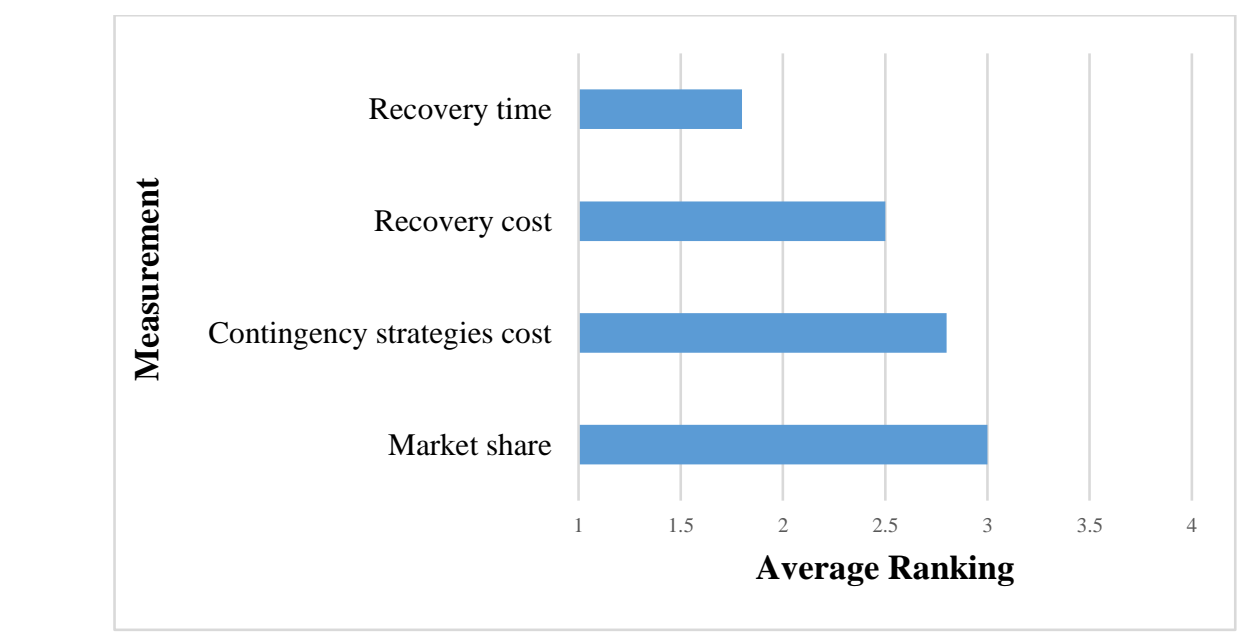

Figure 3 - Measurement of supply chain resilience (from "1" most to "4" least important measurement)

The recovery time appears to be the main measure for capturing the level of resilience. Following a disruption, a company can estimate its resilience level by calculating the time taken to return to normal operating performance. Practitioners ranked the recovery cost as the second most important measurement, which refers to the sum of costs accrued following disruption recovery activities. The third most important measurement 
is the contingency strategy cost, which is based on an evaluation of the economic impact of deploying resilience strategies. According to practitioners, the least important measurement is market share.

\section{Conclusion \& Future Directions}

We contend that resilience is one of the most prominent and, at the same time, difficult research streams related to SCRES. Defining disruptions, and then understanding the level of resilience required, is crucial for improving the overall resilience capabilities in supply chains. The main aim of this work has been to investigate what managers understand as disruptions and resilience and how they measure these constructs. Our design has enabled us to explore the converging and diverging views from academics and managers.

The first research question (RQ 1) aimed to identify the characteristics of supply chain disruptions that decision makers work actively towards avoiding. In relation to what is a disruption, there are clear commonalities between what practitioners and managers perceive to be disruptive events, coalescing around network-based events, demand side risk and quality risks. To categorise these, it could be argued that practitioners focus on operational risks or challenges that occur on a daily basis (low impact, high probability) rather than focussing on potentially higher impact disruptions with wider spread consequences (high impact, low probability). Arguably, once they have built a resilient approach towards these highly probable events, they will have the resources available to face up to more low probability, high impact disruptions as argued in the SCRES literature. To address the second research question (RQ 2), we asked respondents to provide (academics) or to rank (practitioners) strategies that can be deployed for enhancing resilience. The use of flexibility, supply chain design and supply chain collaboration feature across both pools of respondents when referring to resilience strategies employed. Such findings are aligned with previous works on SCRES (Rice and Caniato (2003); Christopher and Peck (2004); Jüttner and Maklan (2011)).

Concerning the third research question (RQ 3), we deepened the analysis in emphasising whether the industry can play a role in defining how resilience is pursued by companies. To this extent, we asked academics to list industries where resilience is considered to be a key concern. We found how complex and global industries, like automotive and electronics, are considered to be more disruption prone. The food industry was chosen for its specific risks like perishability constraints, volatile demand and supply markets. 
Lastly, the fourth research question (RQ 4) sought to capture the metrics considered important for measuring resilience. The debate around this question continues in the literature. Our results suggest an agreement between academics and practitioners on how resilience can be measured. Traditional risk management has focused on evaluating the probability and impact of a risk, whereas both types of respondents refer to the recovery time as the main measurement for assessing resilience. This finding reports applications in the automotive industry, among others, as a distinction between time-to-recovery (TTR) and time-to-survive (TTS) (Simchi-Levi 2015). This, however, seems an inadequate measure for proactively enhancing the resilience of a supply chain and the results show how this area is still far from being understood. While our research aimed at providing more insights into the nature of disruptions and resilience, it also helps in providing future avenues for research on SCRES in the supply chain management discipline.

First, as we focused on three specific industries in the second stage of the study, further research is needed in order to understand how automotive, electronics and food companies generate resilience. That means understanding whether there are practices that are constrained by the application context or there are cross-industry practices going beyond the boundaries of the industry.

Second, as pointed out by Tukamuhabwa et al., (2015), considering the ability of companies to overcome disruptions without embracing cost analysis is an incomplete view. Indeed, companies should be able to bounce back from disruptions in a costeffective way (Hamel and Välikangas 2003; Yao and Meurier 2012). Further research should evaluate how the economic sphere shapes the portfolio of practices that managers adopt for enhancing resilience. In fact, this constraint can potentially lead to a sub-optimal solution.

Third, there is a need to focus on quantifying the level of resilience. As shown by Kamalahmadi and Parast (2016), even if SCRES has become a relevant topic, few studies have tried to propose resilience measures. To this extent, managers can be reluctant to invest resources in strategies for enhancing resilience if they are not able to prove the return or benefits that they will obtain in the long term. The focus on flexibility and timeto-recovery can be interpreted as an indicator of the problems currently faced in this respect. Indeed, creating resilience means improving the ability to proactively prepare for potential disruption and immediately respond by having, for instance, additional resources (Wieland and Wallenburg 2013). Furthermore, considering the highly inter- 
connected nature of companies in today's global landscape, SCRES is determined by the weakest node in the chain. To this extent, previous studies have shown how the concept of resilience is complex and permeates beyond the boundaries of a single company (Craighead et al. 2007; Wakolbinger and Cruz 2011). As we develop our understanding of this phenomenon, we must therefore seek to advance our approach to analysing it.

\section{References}

Bakshi, N., \& Kleindorfer, P. (2009). Competition and investment for supply-chain resilience. Production and Operations Management, 18(6), 583-603.

Barroso, A. P., Machado, V. H., Carvalho, H., \& Cruz Machado, V. (2015). Quantifying the Supply Chain Resilience. In Applications of Contemporary Management Approaches in Supply Chains (pp. 13-36). InTech.

Blackhurst, J., Dunn, K. S., \& Craighead, C. W. (2011). An Empirically Derived Framework of Global Supply Resiliency. Journal of Business Logistics, 32(4), 374-391.

Bode, C., Wagner, S. M., Petersen, K. J., \& Ellram, L. M. (2011). Understanding responses to supply chain disruptions: Insights from information processing and resource dependence perspectives. Academy of Management Journal, 54(July), 833-856.

Business Continuity Institute. (2016). Supply Chain Resilience Report 2016.

Carter, C. R., Rogers, D. S., \& Choi, T. Y. (2015). Toward the theory of the supply chain. Journal of Supply Chain Management, 52(2), 89-97.

Christopher, M., \& Peck, H. (2004a). Building the Resilient Supply Chain. International Journal of Logistics Management, 15(2), 1-14.

Christopher, M., \& Peck, H. (2004b). The five principles of supply chain resilience. Logistics Europe, 12(1), 16-21.

Craighead, C. W., Blackhurst, J., Rungtusanatham, M. J., \& Handfield, R. B. (2007). The Severity of Supply Chain Disruptions: Design Characteristics and Mitigation Capabilities. Decision Sciences, 38(1), 131-156.

Durach, C. F., Wieland, A., \& Machuca, J. A. D. (2015). Antecedents and dimensions of supply chain robustness: a systematic literature review. International Journal of Physical Distribution \& Logistics Management, 45(1), 118-137.

Ellis, S., Henry, R., \& Shockley, J. (2010). Buyer perceptions of supply disruption risk: a behavioral view and empirical assessment. Journal of Operations Management.

Hamel, G., \& Välikangas, L. (2003). The Quest for Resilience. Harvard Business Review, 81, $52-63$.

Handfield, R. B., \& Bechtel, C. (2002). The role of trust and relationship structure in improving supply chain responsiveness. Industrial Marketing Management, 31(4), 367-382. 
Hendricks, K. B., \& Singhal, V. R. (2005). An Empirical Analysis of the Effect of Supply Chain Disruptions on Long-Run Stock Price Performance and Equity Risk of the Firm. Production and Operations Management, 14(1), 35-52.

Jüttner, U., \& Maklan, S. (2011). Supply chain resilience in the global financial crisis: an empirical study. Supply Chain Management: An International Journal, 16(4), 246-259.

Kamalahmadi, M., \& Parast, M. M. (2016). A review of the literature on the principles of enterprise and supply chain resilience: Major findings and directions for future research. International Journal of Production Economics, 171, 116-133.

Knemeyer, M., Zinn, W., \& Eroglu, C. (2009). Proactive planning for catastrophic events in supply chains. Journal of Operations Management, 27(2), 141-153.

Norrman, A., \& Jansson, U. (2004). Ericsson's proactive supply chain risk management approach after a serious sub-supplier accident. International Journal of Physical Distribution \& Logistics Management, 34(5), 434-456.

Pettit, T. J., Fiksel, J., \& Croxton, K. L. (2010). Ensuring Supply Chain Resilience: Development of Conceptual Framework. Journal of Business Logistics, 31(1), 1-21.

Ponomarov, S. Y., \& Holcomb, M. C. (2009). Understanding the Concept of Supply Chain Resilience. The International Journal of Logistics Management, 20(1), 124-143.

Rice, J. B., \& Caniato, F. (2003). Building a Secure and Resilient Supply Network. Supply Chain Management Review, 7(5), 22-30.

Sheffi, Y., \& Rice, J. B. (2005). A Supply Chain View of the Resilient Enterprise. MIT Sloan Management Review, 47(1), 41-48.

Simchi-Levi, D. (2015). Find the Weak Link in Your Supply Chain. Harvard Business Review.

Spekman, R. E. (1988). Strategic supplier selection: Understanding long-term buyer relationships. Business Horizons, 31(4), 75-81.

Tang, C. (2006). Perspectives in supply chain risk management. International Journal of Production Economics, 103(2), 451-488.

Tierney, K., \& Bruneau, M. (2007). Conceptualizing and measuring resilience: A key to disaster loss reduction. TR news, 14-17.

Tukamuhabwa, B. R., Stevenson, M., Busby, J., \& Zorzini, M. (2015). Supply chain resilience: definition, review and theoretical foundations for further study. International Journal of Production Research, 53(18), 5592-5623.

Upton, D. M. (1997). Process range in manufacturing: an empirical study of flexibility. Management Science, 43(8), 1079-1092.

Wakolbinger, T., \& Cruz, J. (2011). Supply chain disruption risk management through strategic information acquisition and sharing and risk-sharing contracts. International Journal of Production Research, 49(13), 4063-4084.

Wieland, A., \& Wallenburg, C. M. (2013). The influence of relational competencies on supply 
chain resilience: a relational view. International Journal of Physical Distribution \& Logistics Management, 43(4), 300-320.

Yao, Y., \& Meurier, B. (2012). Understanding the supply chain resilience: a Dynamic Capabilities approach. In 9es Rencontres Internationales De La Recherche En Logistique (pp. 1-17). 